\title{
An issue of accountability
}

\author{
Cary W. Akins, MD
}

Recently I published an editorial titled, "The Ethical Dilemma of Thoracic Surgery Recertification,"1 which contended that surgeons who choose to practice only one branch of our specialty after initial certification, that is, either general thoracic or cardiac surgery, should be recertified only for the subspecialty of our field in which they practice. In that editorial I acknowledged that the American Board of Thoracic Surgery (ABTS) has established appropriate initial certification criteria and testing modalities to accurately describe those who complete the training and pass the necessary examinations as being competent to independently practice both branches of our specialty.

There is, however, an issue about initial training and certification that must addressed, a crucial issue that makes many older surgeons uncomfortable, namely, justifying in today's world why we require all residents to be trained in both cardiac and general thoracic surgery. Merely citing data that many residency graduates enter employment opportunities where they practice both general thoracic and cardiac surgery is not sufficient justification. What about those residents who have already decided which of the two branches of our specialty they wish to pursue? Why are we burdening them with as much as a year of their residency spent training for a surgical subspecialty they will never practice?

In light of the distressingly low number of applicants for training positions in thoracic surgery in the United States, everyone agrees that we need to reassess what we are doing that might be contributing to our failure to attract the best and brightest in sufficient numbers to satisfy our projected manpower needs. Several authors have addressed this topic, and, indeed, a questionnaire was sent to general surgery residents to see whether there are circumstances or perceptions that we can change. ${ }^{2}$ In that study I do not believe separating training into either general thoracic or cardiac surgery was offered as an option. Half of the respondents agreed that a reduced length of training might influence their decision to apply in thoracic surgery. Extrapolating that concern to some residents potentially viewing added months of training in a subspecialty that they will never pursue as a misuse

\footnotetext{
From the Massachusetts General Hospital, Department of Cardiac Surgery, Boston, Mass.

Disclosures: Author has nothing to disclose with regard to commercial support.

Received for publication April 25, 2012; revisions received April 25, 2012; accepted for publication May 16, 2012; available ahead of print June 18, 2012.

Address for reprints: Cary W. Akins, MD, Massachusetts General Hospital, Department of Cardiac Surgery, White 503\55 Fruit St, Boston, MA 02114 (E-mail: cakins@partners.org).

J Thorac Cardiovasc Surg 2012;144:530-1

$0022-5223 / \$ 36.00$

Copyright (c) 2012 by The American Association for Thoracic Surgery doi:10.1016/j.jtcvs.2012.05.052
}

of their time, requires minimal imagination. The desire for shortened, or at the very least, efficient training programs is in part justified by the fact that almost two thirds of graduates leave medical school more than $\$ 100,000$ in debt.

We need to take an oblique lesson from the current climate in health care accountability that is being espoused in many progressive medical centers, where medical care is now heavily focused on what is best for the patient, not for the caregiver. When physicians concentrate on what is best for patients, the correct answers to most competing agendas quickly become apparent. As cardiothoracic surgeons who design training programs, we need to consider what is best for the training of our residents, not what makes our clinical services work more smoothly or preserves tradition. To force a resident who has already decided that he wants to practice only general thoracic or cardiac surgery to spend almost half of his training period focusing on a completely different intellectual discipline and learning operations that he will never perform is inexcusable. After general surgical training there is no other surgical specialty that does this. Indeed, even the previously sacrosanct requirement for completion of general surgical residency as a prerequisite for training in our specialty has been abandoned.

We must also expand on our growing commitment not to waste training time for residents in the current setting of drastically limited work hours. Most general thoracic or cardiac surgeons would agree that there is an enormous body of knowledge unique to each branch that is necessary to master to become a qualified, proficient clinician. The limitation of work hours has also seriously affected the time residents can spend in the operating room acquiring the requisite technical skills. In many programs rotations alternate between the subspecialties, which only serves to halt what could be a smooth progression of learning that should result in being allowed to advance more rapidly in understanding and technical facility. In addition, time saved could be used to expand exposure to evolving technologies, for example, catheter-based skills in cardiac surgery. We should use the hours for training residents more wisely.

Imagine how applicants for cardiology training would respond if they were told that they needed to devote a substantial portion of their residency to learning pulmonary medicine. We must acknowledge that our two subspecialties have very disparate intellectual foundations that cross over only in the area of organ transplantation. Even our surgical techniques are very different, requiring unique technical skill sets.

In years past, when there were more applicants than there were training positions available and medical care was often 
organized for the benefit of the physician or surgeon, the use, and occasionally abuse, of residents to get a lot of the work done was viewed as an acceptable tradeoff for teaching. Those times have passed. We need to change with the times. We need to offer applicants the option of continuing to be trained in both branches of our specialty as currently exists or to be trained separately in either general thoracic or cardiac surgery, if they so desire.

This is the right time to make this decision. The ABTS in recent years has demonstrated a willingness to consider alternative training models that limit the time required in general surgical residency. Innovative programs have been developed that permit residents to enter our specialty earlier than would have been previously allowed, including directly out of medical school in the Six-Year Integrated model. I believe our thoughtful residency program directors can develop appropriate educational programs for applicants seeking training in only general thoracic or cardiac surgery.

We need to be accountable for our actions as teachers, reconsider our present certification requirements, and focus on what is truly best for some of our applicants who desire to practice only general thoracic or cardiac surgery. In so doing we might attract more of the best and brightest.

\section{References}

1. Akins CW. The ethical dilemma of Thoracic Surgery recertification. J Thorac Cardiovasc Surg. 2012;143:521-2.

2. Vaporciyan AA, Reed CE, Erikson C, Dill MJ, Carpenter AJ, Guleserian KJ, et al Factors affecting interest in cardiothoracic surgery: survey of North American general surgery residents. Ann Thorac Surg. 2009;87:1351-9. 